\title{
Safety, health and hazards related to using of sprayed concrete in underground mining works
}

\author{
Mihaela Toderaş ${ }^{1, *}$, Ciprian Danciu ${ }^{1}$ \\ ${ }^{1}$ University of Petrosani, Mining Engineering, Surveying and Constructions Department, 332006 \\ Petrosani, Romania
}

\begin{abstract}
Sprayed concrete is a traditional building material, but at the same time it represents a highly innovative technology. The development of sprayed concrete includes material science and advances spraying equipment technology. The performance and characteristics of sprayed concrete depend mainly on the condition of its application, equipments, experience and competence of the crew performing the sprayed concrete operation. This paper presents some aspects regarding a sprayed concrete operation that may have multiple hazards due to the equipment, pressure value and the projection of rebound. In addition, the use of sprayed concrete in underground mining works, involve an adequate ventilation in the application area. Special attention has to be given to chemical admixtures and complementary products use in the constituent materials and finally, in the composition of sprayed concrete.
\end{abstract}

\section{Brief history of sprayed concrete}

By realizing an underground excavation, the miners observed with astonishment a peculiar phenomenon that took place on the outline of the cavity, namely that the surrounding rocks tended to open somehow and contrariwise to close in other areas. The idea of trying to find the intact rock around the underground gallery and "fix" it in a certain way is not at all recently; since the $19^{\text {th }}$ century various technics were used in order to support the vaults of the underground excavations $[1,2]$. The history of sprayed concrete is directly related to the restriction of the field of use of conventional cast concrete. Sprayed concrete was used for the first time in 1895 by Dr. Carlton Akeley, who has developed an equipment by means of which the mortar mixture can be sprayed. The equipment developed by Akeley is known as "cement gun", and the sprayed material was called "gunite". In 1911 this method was taken and patented by Cement Gun Company $[1,3]$. The idea to spray concrete instead of cast was launched in 1910 by several mining engineers. Sprayed concrete has a specific composition, adapted to its use, and therefore the name is different in order to distinguish it from ordinary concretes. As a matter of fact, the sprayed concrete is more like a quick setting mortar. Sprayed concrete support has developed around the world as a constructive process for tunnels. Progresses in sprayed concrete technology have enabled the worldwide development of the New Austrian Tunnelling Method (NATM) that was proposed by Rabcewicz in 1962 [1, 2]. Guniting (spraying concrete), as a part of initial support system

\footnotetext{
*Corresponding author: toderasmihaela@yahoo.com
} 
contributes significantly to the mobilization of the rock around the underground work. This mobilization can be achieved by controlling the deformations that occur in the rocks. Using this technique in order to mobilize at maximum the strength that develops in consolidated rocks around the underground work, lead to smaller loads that act on permanent support and thus more economic and practical support system results.

\section{Sprayed concrete components and their consequences}

By definition, sprayed concrete is an artificial conglomerate obtained by setting the homogeneous mixture of aggregates, binder and water in certain proportions. In smaller proportions, other powdered materials are also found in the sprayed concrete composition (slags, ashes etc.) called additions and a number of substances as additives, which modify, in the desired sense, some physical-mechanical characteristics (figure 1).

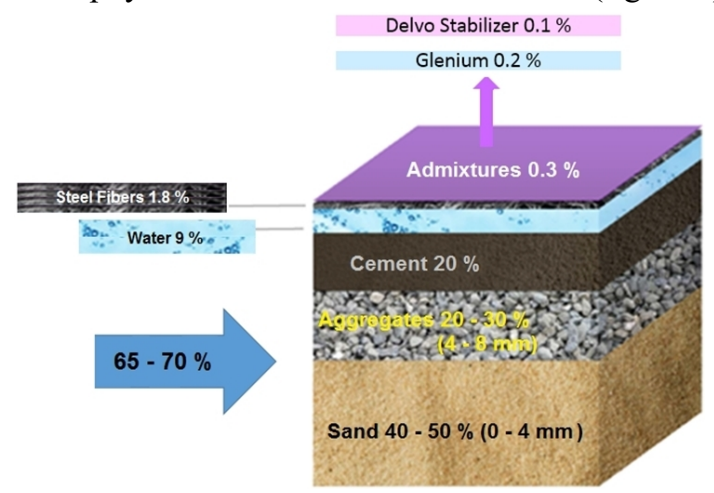

Fig. 1. The components of a typical sprayed concrete mix, in percent, established on the basis of mass values (according to Mahoney, 2014) [3].

The physical-mechanical properties of the sprayed concrete are strictly related to its component elements. Sprayed concrete mixes are founded in various types among which one can be remembered: simple sprayed concrete (unreinforced); sprayed concrete with silica fume; fibers reinforced sprayed concrete with blast furnace slag, having high strengths and performances and different setting properties. The mixture should be conceived to guarantee that the in situ setting of sprayed concrete ensures the development of acceptable mechanical and physical properties. However, the effects associated with its application process, such as compaction, rebound, and fiber orientation, can greatly influence the properties of the setting sprayed concrete. The two key parameters for both wet and dry gunning variants are the water-cement ratio $(\mathrm{W} / \mathrm{C})$ and the grading curve of the aggregates. Most properties of sprayed concrete riche if the $\mathrm{W} / \mathrm{C}$ ratio decrease, including here the strength, permeability and durability. Adding accelerators, silica fume or other component changes the physical properties of sprayed concrete, especially the permeability and durability. The frost-thaw strength of sprayed concrete rises with use of air entraining admixtures, while the use of fibers improves its mechanical strength. Protecting it until setting, plays an important role and improves the mechanical and physical performance properties. It should be underlined that the mechanical and physical properties of sprayed concrete, depend mainly on its application conditions. The equipment and its features, and also the teamwork competence and experience, greatly influence the quality of the spraying concrete. Aggregates used in sprayed concrete have to comply with the requirements of EN 12620 [4], or alternatively with the standards or national regulations valid in the place of use. The typical sprayed concrete mix, sand and aggregates combined, makes up for $65-70 \%$ of the total mass. Sand's and aggregates' quality, has a great importance, because it influences 
the performance of the application of sprayed concrete and final support performance. Combined grading will influence the pumpability, workability and rebound during spraying. In fiber reinforced mix, these two requirements play an even greater role [1, 3, 4]. Similar influence has the shape of aggregates. Fineness, purity and water absorption have a big influence on the water demand, workability, and cement demand and subsequently to the admixture selection. The aggregate distribution must be within a certain grading range accepted by current standards. Due to the fact that the boundaries of the aggregate grading classes are relatively small, it is often convenient to combine two or more fractions (e.g. $0-2 \mathrm{~mm}, 2-4 \mathrm{~mm}$ and $4-8 \mathrm{~mm}$ ) by adjusting the proportions to achieve the type aggregate grading which corresponds to the limits of the grading curve (see figure 2) $[1,3,5]$.

$$
\text { Site ISO, marime ochiuri site [mm] }
$$

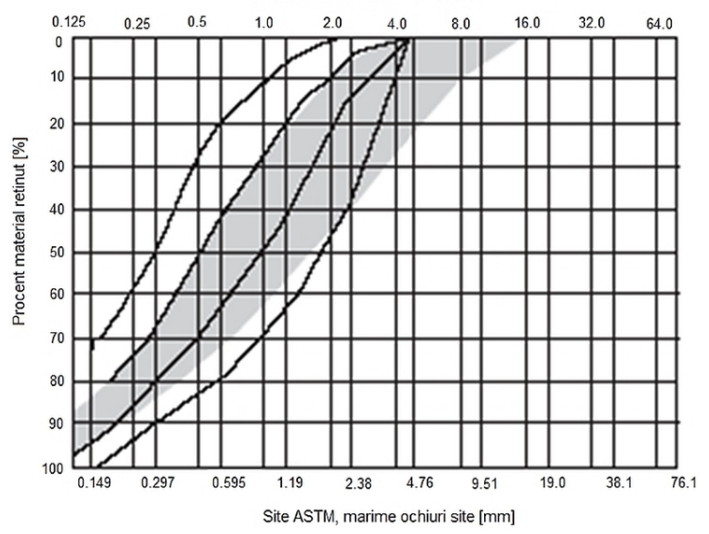

Fig. 2. The limits of aggregates grading classes used in the composition of sprayed concrete and recommended grading zone for aggregates $[1,5]$.

A deficiency of fine material will be offset by using a larger amount of cement or microsilica, and an excess of fine material implies an increase in the dosage of additions to reduce the amount of water. No fraction should measure more than $30 \%$ of total. It is recommended that the percentage of aggregates size of $8 \mathrm{~mm}$ does not exceed $10 \%$ of volume, otherwise it would cause riches when pumped on the surface of the rocks or could penetrate into the previous layer of crack, producing craters that are difficult to fill $[1,3,5]$.

Cements should comply with the requirements of EN197, or alternatively with the national standards or regulations valid in the place of use. Usually cement consists of limestone, clay or clay schist. These materials are extracted from quarries, ground into fine powders and mixed in well-established proportions. The type of cement will be specified taking into account the influence of the current temperature and assessment of heat according to the required application time, the required developed strength and final strength, as well as the durability conditions. Since the sprayed concrete must develop an immediate strength, it is necessary to use a large quantity of clinker to obtain an immediate reaction to fix the accelerators. The 27 types of cements are grouped into 5 categories: CEM I Portland; CEM II Portland-composite; CEM III Blastfurnace; CEM IV Pozzolanic and CEM V Composite. In order to achieve satisfactory results regarding the sprayed concrete, we need to consider not only the type of cement but also other key features such as: clinker content, grading fineness and gypsum content. A lower content than imposed gypsum and aluminate $\left(\mathrm{C}_{3} \mathrm{~A}\right)$ has a negatively influence on the setting and strength characteristics. Minimum cement content will be $300 \mathrm{~kg} / \mathrm{m}^{3}$. The fineness and strength class of chosen cement have a very important role regarding the setting and strength characteristics of sprayed concrete $[1,6]$. The most used additives for sprayed concrete are: fly ash (PFA), ground blast furnace slag (GBFS) and silica fume (microsilica). The last one is composed of about $80 \% \mathrm{SiO}_{2}$ (quartz). It is about 100 times finer than cement and gives a 
relatively good reaction, influencing the following properties of the sprayed concrete: better pumpability; less segregation; fewer rebounds; improves adhesion; improves sealing; prevents sprayed concrete deformation; higher final strength and lower permeability; reduces the alkaline reaction of aggregates; greater durability. Fly ash has a considerable role in the properties of sprayed concrete.

During the mixing process the ash behaves as a mixture of cement or as a substitute for the fine part of the aggregates. Generally, this addition has a positive effect on working/pumping of sprayed concrete and long-term performance regarding the durability. Blast furnace slag (weak reaction with cement) is obtained by rapid cooling of the slag melt and contains $95 \%$ or more oxides (silica alumina, lime and magnesia). Although this additive contributes to pumpability, it is not often used in the composition of the sprayed concrete because it can lead to a slow response to accelerators. It is not often used as an additive in the composition of sprayed concrete due to its limited availability and its adverse effect on the strengthening and development of the initial sprayed concrete strength $[1,5,6]$. The water with which it is mixed, should not contain substances that can affect concrete or steel. Harmful substances can be: sulphate, chloride, alkali, sugars, oil etc. A theoretical value of the amount of water is in the range of a maximum W/C ratio of 0.24 . This minimum quantity of water does not provide a satisfactory workability of concrete required for placing. W/C ratio is important for initial setting and development of strength sprayed concrete, reaching the appropriate value of long-term strength, durability and strength to the chemical attacks. $\mathrm{W} / \mathrm{C}$ ratio must be less than 0.50 and preferably less than 0.45 . Evaporation of water, especially from free surfaces, should be avoided because it leads to insufficient hydration resulting a lower durability. Currently, there are three types of accelerators that are used: based on silicate, the typical dosage being $6-14 \%$ of the weight of cement; based on alumina in an amount of $3-8 \%$ and accelerators based on alkali for which the recommended dosage is $5-10 \%$ of the weight of the cement. Each type of accelerator must be chosen according to the specification, compatibility with the cement and in relation to the local conditions of use of sprayed concrete $[1,5,6]$.

\section{Sprayed concrete particularities}

The particularity of the support made from mortar or spraying concrete consists in the participation of the rocks themselves to achieve the bearing strength $[7,8]$. Thus, the rocks, from the object of the support, became themselves a means of support, basically rocks are self-supporting. In the new formed system, sprayed concrete - rock, the latter has a decisive role in supporting the underground works. Compared to classical support, the sprayed concrete is an active support, involving the rock in the process of taking over the pressure acting on the contour (figure 3). This particularity is explained by the fact that most of the rocks in the monolithic state have higher strengths than the supporting materials. After the blasting operation, on the outline of the mining work a network of cracks is created that leads to the abatement of the cohesion of rocks, gradually causing the separation of the rocks from the massif. Upsetting the concrete and mortar at 0.5 to $0.6 \mathrm{MPa}$ make the small particles of cement and sand to penetrate into the network of cracks until a certain depth; by reinforcing them is achieved a cementing of cracks and a consolidation of the pieces of rock that previously exhibited collapsing tendencies, thus forming on the contour of the underground work a consolidated rock barrier. The mixture spilled on the surface of rocks adheres very well and strengthens in a short time, having a resistance and impermeability superior to conventional concrete. The sprayed concrete is impermeable to water infiltrations at pressures of less than 0.6 to $0.8 \mathrm{MPa}$ and can be used as a temporary and permanent support. 


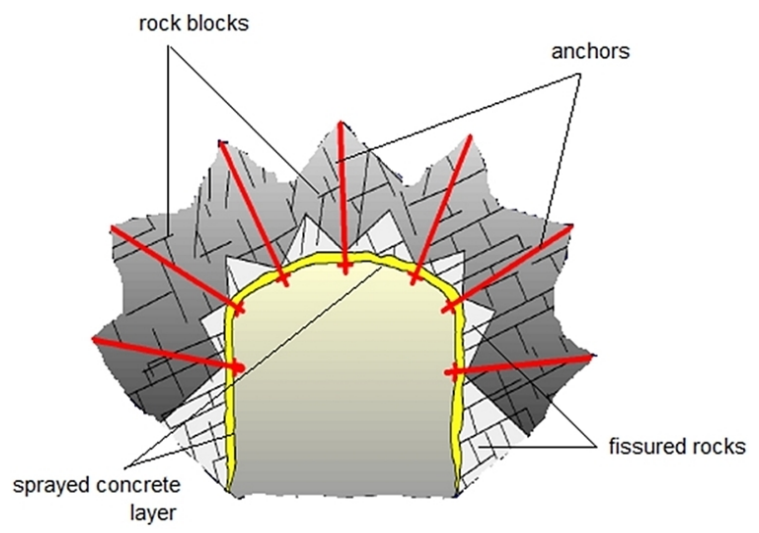

Fig. 3. Mechanism of consolidation of rocks on the contour of underground works (active support sprayed concrete and anchors combined support [5].

As a temporary support sprayed concrete follows closely the face advance and the thickness of the $5 \mathrm{~cm}$ sprayed concrete manages to protect the rocks against alterations, to prevent water infiltration and the formation of scales; application of the sprayed concrete in thin layers of 3 to $15 \mathrm{~cm}$ leads to the appearance of the spring effect that helps to create an intimate interaction with the surface of the rocks. Depending on the application it is basic for material to spray bottom-up, if it is not necessary, to spray the complete profile in one go $[1,3,5,7]$. As definitive support, the thickness of the sprayed concrete layer increases to $50-70 \mathrm{~cm}$ and can be extended to underground works that cross through medium and highstrength rocks with altering tendencies located outside the working faces zones of influence. This variant becomes more efficient than the classic concrete supports. In the case of low-strength rocks for which the underground constructions must have a high supporting power, the sprayed concrete can be associated with metal mesh fixed with anchored supports $[1,5]$.

\section{Security, health and protection to use of sprayed concrete}

Different hazards can be linked by the spraying operation, due to the used equipment, high pressure lines (air, water or material) and the projection of rebound [1, 7, 9]. Underground personnel involved in the spraying process should be aware of a special risk of rock falls or detachment concrete. At the same time, high pressure and velocity of the mass of sprayed concrete and sand and gravel represent a high-risk during spraying. It is imperative to ensure adequate safety and protection measures (wearing protective glasses, dust masks, long sleeved clothing to prevent burns caused by cement etc). Cement can cause dry and cracking skin, dermatitis and alkali burns. The admixtures can cause different problems, especially caustic accelerators. That is why all personnel working in underground must have appropriate protective devices and appropriate coveralls. As regards the underground personnel who are directly involved in the application of sprayed concrete, they must wear protective equipment at all times and ensure adequate ventilation in the application area, because spraying creates dust, mist and other substances that can contaminate the air. At the same time, there is a risk to be protruding reinforcement fibers in sprayed concrete on the contour of underground work and may constitute real dangers, as they can injure the personnel. To avoid this potential risk (hazard) a simple solution is to initially apply a thin layer of unreinforced sprayed concrete $[1,7]$. Special attention must to be given to safety requirements and operation instructions provided by the equipment manufacturer and the materials supplier $[7,8,10]$. Heavy and moving equipment through the high pressure may 
constitute high potential risks for underground personnel working in gallery face in which spraying is achieved. We could say that in such situations there is a tendency in the world to apply the fully automated spraying solution using integrated and automated systems that ensure on the one hand high productivity and controllable quality and on the other hand security and much more friendly work conditions of the operator. In this sense a 3D spraying simulation software was conceived since 2013 (Mayco Logica System) [1]. The advantages of such a remote controlled spraying system are primarily related to: reducing spraying and laboratory tests time; reducing rebound; high productivity, independent of operator skill, surface conditions of the rock and visibility; work conditions are improved, because due to the computer-aided system the operator focuses only on the visual control of the quality of spraying; the spray nozzle is automatically maintained at the correct distance and correct angle with respect to the surface of the rocks on the contour of the work, even in areas where visibility is reduced, thus achieving better consolidation and less rebound $[1,3,5,6]$. Admixtures and water reduction admixtures in particular, but also complementary products, are generally considered to be harmful to humans and to the environment. Due to their corrosivity, it is recommended to use alkali-free accelerators. Since some accelerators are acidic and corrosive to metals, stainless steel or plastic containers are required $[1,7,11]$. Accelerators based on silicate have a high alkali content $\left(\mathrm{Na}_{2} \mathrm{O}\right), \mathrm{pH}>11$ and require personal protection against skin and eye irritation; risk of alkali silicate reaction (ASR) and leaking water-soluble portions occurs. Accelerators based on aluminates are caustic, with $\mathrm{pH}>12$ and require personal protection against skin and irritations. Alkali-free accelerators $\left(\mathrm{Na}_{2} \mathrm{O}<1 \%\right)$ are preferred because they are less hazardous (non caustic) and provide a better working environment $[1,3,5,11]$. When working after the dry-mix method, operators are very exposed to a lot of dust. Dust emissions are located not only at the nozzle level but also at the spraying machine. Measurements of fine dust in the working atmosphere gave results greater than three times of the amount of permitted dust (usually $6 \mathrm{mg} / \mathrm{m}^{3}$ air). In Figure 4 are shown the ranges of fine dust measured at $6 \mathrm{~m}$ behind the excavation face during the application of sprayed concrete by means of different dry-mix spraying method $[1,9]$.

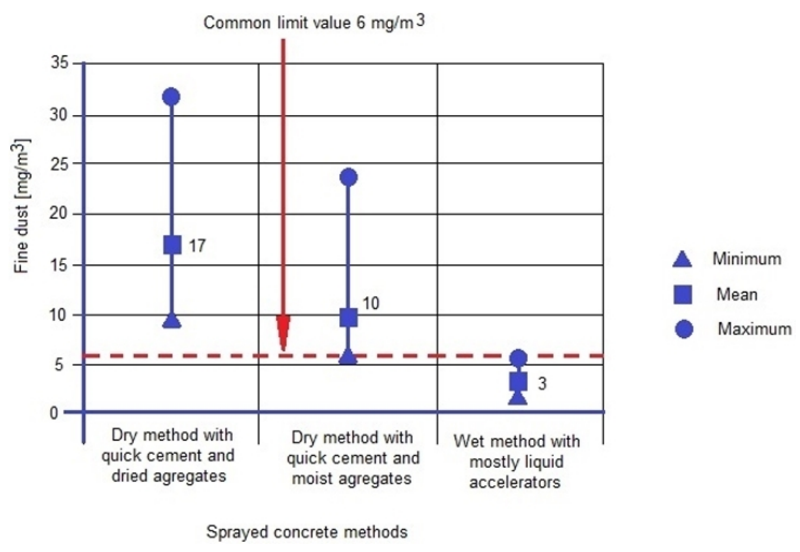

Fig. 4. Ranges of fine dust concentrations measured $6 \mathrm{~m}$ behind the excavation face during application of sprayed concrete (according to Lukas, 1998 [8]).

From the studies carried out by different specialists in the field $[1-3,5,6]$ it is found that using the wet-mix method, the amount of fine dust present in the working atmosphere is below the maximum allowed value. Dust measurements in the immediate environment of the spraying operator at different spraying systems, are shown in Table 1. The leaching of admixtures risk from sprayed concrete to the environment is low, and the impact to the environment is negligible. 
Table 1. The amount of dust in the environment of the spraying operator [1].

\begin{tabular}{|c|c|c|c|}
\hline Spraying method & $\begin{array}{c}\text { Relative dust intensity } \\
{\left[\mathbf{m g} / \mathbf{m}^{\mathbf{3}} \mathbf{a i r}\right]}\end{array}$ & $\begin{array}{c}\text { Spraying capacity } \\
{\left[\mathbf{m}^{\mathbf{3}} \mathbf{h}\right]}\end{array}$ & $\begin{array}{c}\text { Number of } \\
\text { nozzles }\end{array}$ \\
\hline Dry-mix & 12.6 & 13.5 & 2 \\
\hline Dry-mix & 6.6 & 6.8 & 1 \\
\hline Wet-mix & 3.3 & 15.4 & 1 \\
\hline
\end{tabular}

\section{Conclusions}

The sprayed concrete support is an active support, involving the rock to ensure the stability of underground works and implicitly, in the process of taking over the pressure acting on the contour. The sprayed concrete also provides protection against fire and rock corrosion on the contour of underground works, a phenomenon that occurs at the contact of the uncovered rock with the underground atmosphere. The used spraying methods have different influences on the underground working environment. Thus, the use of the wet-mix spraying method has a positive effect on the air quality in the working face and no air pollution was observed, if additions or alkali-free accelerators are introduced in sprayed concrete, then the work environment improves significantly. Rebound of the sprayed concrete consist mostly of aggregates, and its impact on the environment is not relevant. Modern sprayed concrete technology provides important contributions to protecting the environment: less energy used, less water and less waste. Modern sprayed concrete technology contributes substantially to the safety of the entire working environment. The used chemical substances have been exposed to risk assessment studies. Due to advanced admixtures, the working environment has reached a very satisfactory level from the point of view of potential risks. By using fully mechanized equipment and new technologies, the volume of rebound will be very low (less than 10\%), almost no dust formation; during spraying, the air in the working front will be very little polluted or not at all, and no leaching of harmful chemicals to the underground environment will occur. Advanced equipments allow underground personnel to work from the safe distances to working face.

\section{References}

1. ***, Sprayed Concrete for Ground Support (Master Builders Solution, Construction Chemicals Europe Ltd. $13^{\text {th }}$ edition, 2014)

2. M. Karacus, R.J. Fowell, $7^{\text {th }}$ Regional Rock Mech. Symposium, Sivas, Turkey (2004)

3. W. Mahoney, Sprayed Concrete in General Constituents and Mix Design, (Master Builders Solution, Workshop Switzerland, 2014)

4. EN 12620, Aggregates for concrete (2013)

5. L. Hage, Sprayed Concrete in General Fields of Application, Features and Methods (Master Builders Solution, Workshop Switzerland, 2014)

6. B. Lindlar, M. Jahn, Construction Sika, No. 8501202 (2010)

7. M. Toderaş, Mecanica rocilor, pământurilor şi construcţii subterane (Editura Universitas, Petroşani, 2014)

8. L. Krupnik, Yu. Shaposhnik, S. Shaposhnik, A. Konurin, Min. Miner. Depos. 11, 1 (2017)

9. W. Lukas, Schriftenreihe des Osterreichischen Betonvereins, no. 35 (1998)

10. D. Păsculescu, L. Pana, V.M. Păsculescu, F. Deliu, Min. Miner. Depos. 13, 2 (2019)

11. Sr.J. Wolsiefer, D.R. Morgan, CAMET/ACI International Workshop on the Use of Silica in Concrete, Washington, D.C., USA (1991) 